\title{
Energy Supply and Climate Change in Nigeria
}

\author{
AKINYEMI, Opeyemi* OGUNDIPE, Adeyemi ALEGE, Philip \\ Department of Economics and Development Studies, Covenant University, Ota.Ogun State. Nigeria \\ opeyemi.akinyemi@covenantuniversity.edu.ng.
}

\begin{abstract}
The energy industry has been identified as one of the sectors most vulnerable to the impact of climate change. In the past years, government had been making a lot of effort at reforming the energy sector and this study attempted to investigate the extent to which the energy sector will be affected in the face of the threats presented by a changing climate. The study seeks to examine the impact of climate change on energy supply in Nigeria for the period 1971-2011 using the vector error correction procedure. We adopted the Johansen and Juselius, and Engle-Granger co-integration analysis to determine the rank of the series long run co-integration. Also the error correction model was used to obtain the long-run estimates and the speed of error adjustment. We corroborate our findings by adopting the Wald exogeneity test to examine the direction of causal relationship between climate change and energy production. The study found a positive relationship between climate change and energy supply, as well as no evidence of causal relationship between climate change and energy supply. The study developed an interaction of climate change and measure of institutional quality, though less responsive to energy supply, but exhibits similar pattern with the actual climate change. Also, the indicators of power losses, technology and investment impacts a significant negative influence on energy supply, while GDP per capita and economy structure exerts though positive but the indicator of economic structure was statistically insignificant in explaining dynamism in energy supply. The findings from our empirical investigation puts caution on economic advisers and policy makers on the level of adherence to the Kyoto protocol in order not to jeopardize productivity activities and economic gains. Also,adaptation efforts should however follow careful scenario analysis with a strengthened institutional framework and injection of funds for technological improvement. This could be done in partnership with international organizations and the private sector
\end{abstract}

Keywords: Climate Change, Energy Production, Co-integration, Error Correction Model, Causality JEL Classification: Q5, Q43, C2

\subsection{Introduction}

To what extent will changing climate being experienced all across the globe in various dimension impact the energy industry? What coping strategies or mechanism are available in addressing this critical menace that has been regarded as one of the greatest threat to humanity in the $21^{\text {st }}$ century? These are issues on top agenda for policy makers all around the world. Energy is very vital in driving the growth and development of any economy as it is an essential input to a nation's growth and development (Akinbami, 2009)and also strategic to increasing the competitiveness of any economy (Adenikinju, 2008). The energy sector plays a key and central role in the growth and development of any nation, therefore, the reliable and adequate supply of energy is essential to support economic activities and industrialization efforts that will enhance income and standard of living. This is evident in the fact that any form of shock in the sector automatically reverberates into other sectors of the economy as all the sectors require energy for power. The use of energy is, therefore, a prerequisite for virtually all economic activity, and it is crucialto be able to access sufficient amounts of energy at acceptable cost (both from an economic and environmental perspective), which gives rise to the notion of 'energy security' (Greenleaf et al, 2009).

As stated by Oyedepo (2012), access to energy is a crucial enabling condition for achieving sustainable development. Thus, adequate access to sustainable energy is vital. The emphasis here is on sustainability which will ensure that energy is produced in an environmentally friendly manner sustainable for future generations. This brings to bear the fact that energy as a key driver of social and economic development must be environmentally friendly to bring about sustainable economic development. According to Oyedepo (2012), the fuel driving the engine of growth and sustainable development is the nation's access to reliable and adequate energy. No economy can sufficiently thrive without adequate access to clean, reliable and affordable sustainable energy. This is in line with the fact that many of the developmental goals set by economies of the world ranging from eradication of poverty, improvement in health status, provision of basic human needs, amongst others, may not be achievable in the absence of a sustainable energy. Onyeji (2010) asserted that Africa's long term economic growth and competitiveness fundamentally depend on reliable access to energy. Given this key role that energy plays in the economy, one of the threats to its sustainability will be environmental degradation one of which is the incidence of climate change.

In the past, national energy agenda have focused on supply security which has been achieved using domestic resources, however, in recent times, environmental and market liberalization debates continues to increasingly 
dominate policy and influence the fuel mix in new directions (Chalvatzis and Hooper, 2009). Also, most part of key objectives of many energy policies in various economies entails ensuring environmentally sustainable energy production and use. Others cover stability of energy prices, secure energy supplies and a robust infrastructure for delivery and distribution. It is equally evident that the world economy will require an everincreasing amount of energy to sustain economic growth, raise living standards and reduce poverty in the coming years and the availability of this in an environmentally friendly environment is what will guarantee its sustainability for the coming generation. In placing Nigeria at the fore front of economic development, adequate supply of energy becomes an issue that cannot be overemphasized. In the study conducted by the Building Nigeria's Response to Climate Change (BNRCC, 2011), the vulnerability of various sectors of the Nigerian economy were presented, showing that virtually all the sectors manifested evidence of vulnerability to climate change; one of which is the energy sector.

This paper examines how the energy industry will be affected by climate change which is regarded as one of the greatest threat to humanity in the $21^{\text {st }}$ century. Considerable efforts have been made in assessing the causal link between energy consumption and economic growth, but very few studies have examined how environmental challenges such as the incidence of climate change will significantly impact energy supply which is regarded as the bane of economic growth. Most researches in the aspect of impacts of climate change on the energy sector are in form of technical reports; some others examine how the energy sector contributes to climate change and not so much on how the energy sector will be affected by the incidence of climate change. This paper will attempt to fill this gap in addition to examining the long run relationship between climate change, proxied by $\mathrm{CO}_{2}$ emissions and energy production.

The rest of the paper is organized as follows: section two deals with issues of energy supply and climate change, section three presents some stylized facts and trends on some climate change indicators and energy supply in Nigeria. Section four discusses issues in the literature, section five presents the model and methodology for the paper, while section six discusses the results and policy recommendations.

\subsection{Conceptual Issues: Energy Supply and Climate Change.}

The supply of energy entails the generation, transmission and distribution of energy, notably electricity. Nigeria has an abundant supply of energy resources as it is endowed with thermal, hydro, solar, oil resources and yet still described as an energy-poor country (Ubi and Effiom, 2013). Despite considerable efforts by government and stakeholders to enhance energy supply, the country is still marked with low generating capacity relative to installed capacity. Climate change on the other hand, has been variously defined in the literature to be a definite change in the climatic condition of a region which could be attributed to natural variability and anthropogenic (man-made) activities that persists for an extended period of time. According to the Intergovernmental Panel on Climate Change (IPCC) definition, it is the statistically significant variations that persist for an extended period, typically decades or longer. It includes shifts in the frequency and magnitude of sporadic weather events as well as the slow continuous rise in global mean surface temperature (Ifeanyi-Obi et al, 2012). It is regarded as one of the major threats to humanity in the $21^{\text {st }}$ century which has sparked off a lot of policy debate even in the international scene as its impact cuts across different sectors of the economy, one of which is the energy sector. As its effect permeates through all sectors of an economy it thus presents implications for sustainable national development in terms of sustainability, equity and growth (Akinbami, 2009).

Climate change manifests in the form of increasing temperatures and variations in rainfall patterns and the experience of Nigeria in recent times where some parts of the country have been experiencing seasonal droughts and excessive flooding are all indications that the change of climate experience is evident in the country. The Nigerian government acknowledges the importance of developing an appropriate response to the climate change issue and one of the steps taken is the establishment of the National Adaptation Strategy Plan of Action on Climate Change in Nigeria (NASPA-CCN).

Global efforts in addressing climate change started in the 1980s with the First Assessment Report of the IPCC in 1990 and the United Nations Framework Convention on Climate Change (UNFCC) in 1992. Also, in 1997, the Kyoto protocol was another form of measure put in place in tackling the issue of climate change and it was aimed at setting emissions reduction targets for most developed countries. The International Energy Agency (IEA) estimated that about one thousand policies have so far been put in place since 1990 to combat the menace of climate change. So it is clear that significant action is being taken, what is, however, less clear is how effective these actions have been (World Energy Council, 2007). In most of these policies, especially climate and energy security policies are often focused on using the energy industry to tackle climate change by calling for significant reduction in $\mathrm{CO}_{2}$ emissions (one of the main greenhouse gases (GHGs)). This is in view of the notion that the energy sector is the main contributor to the concentration of GHGs which results to global warming. The energy industry in Nigeria can be said to follow this notion as it is regarded as one of the highest gas-flaring nation and this contributes to climate change. The country, like the rest of Africa is also considered highly vulnerable to climate change impact due to characteristics such as, high exposure and sensitivity to climate 
change; limited adaptive capacity in its current state of development; and large proportions of the population are subjected to other stresses such as poverty, illiteracy, food security, malnutrition and diseases, all of which could interact with climate change (Enete et al, 2012) and create problems of sustainability.

Closely related to the issue of climate change are mitigation and adaptation options as measures of policy responses to climate change impacts. On one hand, mitigation talks about efforts at reducing the negative impacts of climate change, while adaptation calls for means of adapting to the effects of climate change. While mitigation is necessary to reduce the rate and magnitude of climate change, adaptation is essential to reduce the damages from climate change that cannot be avoided. Dixon (2003) as cited in Ifeanyi-Obi et al. (2012), defined adaptation as adjustments in practices, processes or structures in response to projected or actual changes in climate with the goal of maintaining the capacity to deal with current and future changes. In other words, adaptation to climate change refers to activities that reduce the negative impacts of climate change and/or takes advantage of new opportunities that may be presented (Ifeanyi-Obi et al, 2012). With adaptation, differences exist in opportunities and capacity to adapt across regions. Global climate is changing and even dramatic curbs to emissions will not prevent it from continuing to do so and this raises the question of how economies should adapt to changing climatic conditions (Millner and Dietz, 2011). Today, adaptation is increasingly seen as an essential and integral part of proposed and implemented climate policy (Enete et al, 2012). According to IPCC (2007) report, there is high agreement and much evidence that with current climate change mitigation policies and related sustainable development practices, global GHG emissions will continue to grow over the next few decades. This supports the growing call for adaptation as a policy response to climate change especially in developing countries who are regarded as being most vulnerable to climate change impact (due to unfortunate geography and high sensitivity).

\section{$2.1 \quad$ Impacts on Energy Supply}

Scientific reports and researches (CCSP, 2008; BNRCC, 2011; Ebinger and Vergara, 2011; Schaeffer et al, 2011; Beecher and Kalmbach, 2012; US Department of Energy, 2013) made available for policy-makers have predicted that climate change will have adverse effect on the energy sector. The US Department of Energy (2013) asserts that changing climate trends which are expected to continue can restrict the supply of secure, sustainable and affordable energy which is critical to the nation's economic growth. Climate change will significantly affect the energy industry through many ways (Schaeffer et al, 2011). This can happen when rising temperature, irregular precipitation, rise in sea level, among others, affects energy infrastructure and the capacity to mainly produce energy through hydro and thermal sources. BNRCC (2011) asserted that hydropower generation is the energy source most likely to be affected by climate change as it is sensitive to the amount, timing and geographical pattern of precipitation as well as temperature. The report stated further that reduced flows in rivers and higher temperature reduces the capabilities of thermal electric generation as higher temperatures also reduces transmission capabilities. Also, excessive drought will lead to higher evapotranspiration that adversely affects water volume thereby reducing hydroelectric capacity. Furthermore, climate change-induced extreme weather events such as windstorms and floods will exacerbate the rate of failure of transmission system of electric utilities (BNRCC, 2011).

According to Greenleaf et al (2009), extreme weather conditions can temporarily disable energy infrastructures and thus supply of energy. A recent example is theimpact of Hurricane Katrina, which hit the Gulf of Mexico in 2005, disabling a significant portion of the US oil and gas production and processing capacity. The analysis of this impact is essential due to how climate change engages the energy sector closely been that energy is central both to the problem and the solution. It has been forcing governments to redesign the structure of the world energy system and consumption patterns which have made it imperative to consider more efficient and better ways to ensure energy security. Top on the agenda of policy-makers has been the call for increased optimization of renewable source of energy and adoption of low carbon source of modern energy as possible solutions. Over the years, as a means of tackling the negative consequences of climate change, the energy sector has always been the target of policy-makers as the sector is considered the major contributor to the concentration of greenhouse gases in the atmosphere which results to climate change.The same way the energy system significantly contributes to climate change, so also will climate change manifesting in form of rising sea levels, heavy storms, floods, high winds and shoreline erosion likely affect energy facilities and infrastructure.

According to the Climate Change Science Program (CCSP, 2008) report, concerns about climate change impacts could change perceptions and valuations of energy technology alternatives, any of which could have implications for energy policies, decisions, and institutionsin the United States, affecting discussions of courses of action and appropriate strategies for risk management. Also as indicated in the BNRCC (2011) report, climate change will most likely negatively impact the already limited electric power supply through its impact on hydroelectric and thermal generation coupled with service interruption which is expected to result from damage to transmission lines and substation equipments being damaged by sea level rise, flash floods and other extreme weather events. Thus, calls towards addressing climate change impacts on energy system often focuses on the optimization of renewable energy and low carbon development as prominent possible solutions.It is important to note that the 
problems affecting energy sector in developing countries differ from the problems that influence the same energy sector in developed countries (Oricha and Olarinoye, 2012) and with the threat of climate change, the nature of these impacts will differ as well.

In assessing the impact of climate change on the energy industry in United States, the US Department of Energy stated that three main climate trends are relevant to the energy sector and they include increasing air and water temperatures, decreasing water availability in some regions and increasing intensity and frequency of storm events, flooding and sea level rise. Also, the impact of climate change on the energy sector is often assessed in form of impacts on energy supply, demand, transmission, distribution and infrastructure; or indirect effects through other economic sectors. The most common aspect often analyzed in empirical literature is the demand and supply side. While the demand side examines climate change effects on use of energy by consumers, the supply side considers the effects of climate change on production, distribution and transmission of energy. The focus of this study would, however, be on energy supply. The relationship between climate change and the energy sector is important especially considering the bi-directional flow between the two, where as energy use and production contributes to climate change, policies are also targeted towards the energy industry in tackling the climate change menace.With the energy sector been one of the key sectors most vulnerable to climate change impact, coupled with the current epileptic nature of energy supply in Nigeria, there is a need to explore how energy supply will be affected in the face of the threats presented by climate change. This is given the aim of government at increasing electricity generation capacity to $25,000 \mathrm{MW}$ by 2020 from the current installed capacity of $6500 \mathrm{MW}$ while also pledging to connect 75 per cent of the population to the grid from the current 40 per cent by 2025 (Gujba et al, 2010).

\subsection{Stylized Facts}

This section presents some facts and trends in climate change and energy supply in Nigeria. Nigeria is blessed with an abundant reserve of energy resources which ranges from oil, natural gas, water, solar, to wind energy amongst others. According to Adenikinju (2008), Nigeria sits astride of over 35billion barrels of oil, 187 trillion cubic feet of gas, 4 billion metric tons of coal and lignite, as well as huge reserves of tar sands, hydropower and solar radiation among others. Unfortunately, the country has not been paying adequate attention towards the development of these essential energy resources which results to underutilization. According to Adenikinju (2008), the attention had rather been concentrated on the development, exploitation and utilization of crude oil and gas for fiscal objectives. This is supported by Osueke and Ezeh(2011) who stated that only four sources of energy resource (coal, crude oil, natural gas and hydro) are currently being utilized in processed forms while two others (wood fuel and solar) are used in their crude forms for heating, cooking and lighting.

Variations in weather conditions being experienced in Nigeria, coupled with future estimates of changing climate, shows that climate change is indeed here. The Nigeria Meteorological Agency (NIMET, 2008) assessed the Nigerian climate over the period 1941 to 2000 and identified some changes (BNRCC, 2011). The report showed that some regions, notably northeast, northwest and southeast experienced late onset of rains for the period 1941 to 1970 , but from 1971 up on until 2000, many other parts of the country had begun experiencing late onset of rains. Also, climate scenarios used for projecting future climate showed that changing climate will keep increasing.

Table 1: Projected Key Climate Change Parameters by ecological zone:

\begin{tabular}{|c|c|c|c|c|}
\hline Climate variables & Mangrove zone & Rain forest & Tall grass (savanna) & Short grass (Sahel) \\
\hline Temperature & $\uparrow$ & $\uparrow$ & $\uparrow$ & $\uparrow$ \\
\hline Rainfall amount & $\uparrow$ & $\uparrow$ & $\downarrow$ & $\downarrow$ \\
\hline Rainfall variability & $\uparrow$ & $\uparrow$ & $\uparrow$ & $\uparrow$ \\
\hline $\begin{array}{l}\text { Extreme rainfall } \\
\text { events - droughts }\end{array}$ & Likely & Likely & $\uparrow$ & $\uparrow$ \\
\hline $\begin{array}{l}\text { Extreme rainfall } \\
\text { events - storms and } \\
\text { floods }\end{array}$ & $\uparrow$ & $\uparrow$ & Likely & Likely \\
\hline Sea level rise & $\uparrow$ & NA & NA & $\mathrm{NA}$ \\
\hline
\end{tabular}

Legend: $\uparrow$ likely increase or increase; $\downarrow$ likely decrease or decrease; NA not applicable.

Source: BNRCC (2011)

This shows that for most of the regions in Nigeria, rainfall and temperature will tend to be on the increasing side which supports the many calls for adaptation strategies to be put in place.

Also, between 1970 and 2003, $\mathrm{CO}_{2}$ emissions, one of the main GHGs grew by about 80 per cent. As stated in Alege and Ogundipe (2013), the High Emission Scenario (HES) suggested that by 2025, Ghana, Nigeria and Sierra Leone will emit 4.4, 54 and 1.2 million tons of carbon respectively which would amounts to seven, six and 
four folds increase over present emissions. Scientists have noted that the average temperature of the earth has increased by 0.74 degrees Celsius over the past 100 years and if nothing is done, there is going to be more rise in the earth's temperature to the extent that it would be difficult to cope with it (Ifeanyi-Obi et al, 2012).

It is a known fact that Nigeria's energy demand far outstrips its supply. Even with a population of about 148 million people, only about 51 per cent (WDI 2010 estimate) have access to electricity in Nigeria as against the 76 per cent and 61 per cent for South Africa and Ghana respectively. Most of this electricity is provided by standby generating sets acquired by industries, commercial establishments and individuals. This is evident as the Nigerian energy sector is marked by low generating capacity relative to installed capacity as current generation capacity ranges between 2,500megawatts to about 3,000megawatts while estimated national consumption is in excess of 10,000megawatts (Ubi et al, 2012). Despite electricity generation increasing from about 532MW in 1972 to about $6500 \mathrm{MW}$ in 2005, electricity supply is estimated to still be far below the estimated demand of 10,000MW (Gujba et al, 2010). A number of factors have been attributed to this inadequate utilization of energy capacity, some of which includes low development in the sector, inadequate funding, mismanagement and lack of maintenance. Present government is however, aiming at increasing power generation capacity from the current $6500 \mathrm{MW}$ to $10000 \mathrm{MW}$ by 2010 and over $25000 \mathrm{MW}$ by the year 2020 ; with about 75 per cent of the population being supplied electricity by 2025. Gujba et al. (2010) however pointed out that these plans will inevitably lead to disruptive changes in the energy systems in terms of environmental, economic and social impacts.

\subsection{Brief Review of Literature}

A number of factors affect adequate supply of energy in Nigeria which according to Ubi et al. (2012) is the key constraint to industrialization and economic development in Nigeria. This, was attributed to the inability of policy makers to identify the determinants of electricity supply for actual policy formulation and implementation. Also, low level of investment in the electricity sector equally contributes to low generating capacity of the Power Holding Company of Nigeria (PHCN) in Nigeria (Ubi et al, 2012). Iwayemi (2008) attributed the poor supply of electricity to high levels of power and revenue losses, both technical and nontechnical. In the same vein, Ubi et al. (2012) recognized the nature of the energy mix and state of technology in Nigeria to be major determining factors for the supply of energy. However, with all these factors and coupled with recent reports on the vulnerabilities of the energy sector to climate change, changing climate can tend to be a determining factor.

In empirical research, considerable attention has been given to climate change and how it impacts the various sectors of an economy (such as agriculture, construction, health, energy, law, poverty, gender, and so on).However, in the area of energy and climate change, a limited number of studies are available as most studies focus on how the energy sector significantly contributes to the concentration of GHGs in the atmosphere leading to global warming and the relationship between energy consumption and $\mathrm{CO} 2$ emissions. In examining the relationship between energy and its environmental implications, many focus on assessing the linkages among electricity supply, carbon emissions and economic growth (Madison and Rehdanz, 2008). A number of the researches in the area of climate change impacts on the energy sector are often in form of reports prepared for policy makers in various countries. These reports provide informative reviews on specific segments in the energy sector and how vulnerable they will be to the effects of climate change.There is the Climate Change Science Programme (CCSP) Synthesis and Assessment Report (2012) which builds on two previous assessment implications by the CCSP Synthesis and Assessment Report (2007) and the USGCRP Global Climate Change Impacts in the United States (2009). It presents a summary of the currently existing knowledge especially emerging findings since 2007 about implications of climate change for energy use, energy supply (oil and gas, thermal electricity, renewable energy, integrated perspectives and indirect impacts on energy systems) and also future risk management strategies, research gaps and movement towards a self-sustained continuing assessment capacity.

The World Energy Council (2007) report examined the impact of existing climate change measures and how they have been in promoting sustainable development, using the " $3 \mathrm{~A}$ 's" criteria (accessibility, acceptability and availability). Looking at what drives greenhouse gas emissions from the energy sector and how the policies introduced has so far fared, the WEC study concludes that government and others have not been up to the challenge. Policies have been too narrowly focused and short term, failing to provide the right signals for cleaner and more sustainable investment. The WEC report showed that no single policy or measure can provide the whole solution or even the main part of the solution as all available measures have their own drawbacks and advantages. Mideksa and Kallbekken (2010) reviewed the impact of climate change on the electricity market by looking at current and existing knowledge on how electricity demand and supply would be affected by climate change. Schaeffer et al. (2011) presented a review of the energy sector vulnerability to climate change impacts throughout the energy chain by examining contributions of a number of authors in this field. Chalvatzis and Hooper (2009) provided a comprehensive theoretical base for the assessment of supply security at the national 
level and the impact of climate change related regulations for selected European Union countries (Germany, Greece, Poland and the UK). Their study provided insights and suggestions that allow for an improved understanding of the trade-offs and synergies that various policy options may introduce. The report by Greenleaf et al (2009) also indicates that the introduction of a number of climate change policies in the EU will change the structure of the energy system significantly. Matsuo et al. (2012) used the MARKAL model which is a linear programming model for energy system analyses, to find the effects that constraints on co2 emissions will exert on the world's energy supply, demand, structure and costs for OECD and non-OECD regions.

For Nigeria, a limited study however exists. Akinbami (2009) assessed the implication of the climate change and energy system interactions for sustainable development in Nigeria, calling for a more proactive action by government in terms of mitigation technologies. Enete and Alabi (2011) also examined the influence of climate change on power generation by reviewing key literatures in this area and found indications that climate change undermines power and energy production by increasingly depleting renewable and non-renewable sources. They however proposed that in reducing climate-induced threats on power sector, efforts should be geared towards ensuring that the energy sector is able to withstand the changes to climate by optimizing energy mix, developing low carbon and renewable energy. In the same vein, Nnaji et al. (2013) investigated the causal relationship among electricity supply, fossil fuel consumption, $\mathrm{CO} 2$ emissions and economic growth in Nigeria for the period 1971-2009 in a multivariate network. Their findings indicated that economic growth is associated with increased $\mathrm{CO} 2$ emissions while a positive relationship exists between electricity supply and $\mathrm{CO} 2$ emissions, revealing the poor nature of electricity supply in Nigeria. As asserted by Nnaji et al. (2013), existing literature on energyeconomy-environment link over the past two decades indicates that most studies focused on the nexus of energyeconomy or environment-economy with controversial and inconclusive results. Gujba et al. (2010) set out to analyze the implications of the Nigeria energy policy in Nigeria, presenting the life cycle environmental and economic analysis of the current and future electricity sector. There analysis showed that all the life cycle impacts and economic costs increase significantly over the time period studied where renewable sources proposed by government were recognized to reduce environmental impacts of electricity mix. However, this will require a five-fold increase in grid investments by 2030 .

Another solution often advocated for tackling impacts of climate change on the energy system is the adequate mix of energy. This Uzoma et al. (2012) related with sustainable development in Nigeria and asserted that no single energy mix can sustainably meet the energy demands of any country. Therefore, integrating all exploitable energy resources is a viable way of achieving stability in energy supply in Nigeria. Using linear regression(Ordinary Least Square) estimation procedure, they found that existing energy mix has not significantly influenced sustainable development given that electricity generation is inadequate and coal is no longer in use. Ubi and Effiom (2013) who explored the relationship between electricity supply and economic growth in Nigeria found per capita GDP, lagged electricity supply, technology and capital to be significant variables that influence economic development in the country. Ubi et al. (2012) carried out an econometric analysis of the determinants of electricity supply in Nigeria using a parametric econometric methodology of OLS and their results showed technology, government funding and the level of power loss to be the statistically significant determinants. Adenikinju (2008) examined the efficiency of the energy sector in enhancing competitiveness of the Nigerian economy. In addition, Oricha and Olarinoye (2012) analysed the interrelated factors affecting efficiency and stability of power supply in Nigeria. Some of the factors highlighted include government policy, economic factor, natural factor, community factor, effective energy management, skilled personnel, efficient technology and security factor.

In terms of adaptation options, Ebinger and Vergara (2011) focused on energy sector adaptation rather than mitigation in examining how the energy sector might be impacted by climate change and the options available for management. Evidence from their study showed that energy services will be increasingly affected by climate change. On the other hand, Akinbami (2009) recognized the currently commercially available mitigation strategies to include improved supply and distribution efficiency in the power and oil and gas sector, fuel switching from coal to gas, nuclear power, renewable sources (hydropower, geothermal, solar, wind and biomass).

\subsection{Methodology}

This section presents the model, methodology and data sources of energy supply and climate change. The study adapted a model similar to Ubi et al. (2012). The theoretical framework of the model as used by Ubi et al. (2012) was rooted in the basic elementary theory of supply. In this study, the elementary supply theory is augmented in order to capture specific uniqueness of the Nigerian economy and to appropriately ascertain the determinants of energy production in the context of weak institutional quality. A straightforward application of the model can be represented as follows;

Eprd $=f($ clmc, gpci, pwls, invt, estr, tech, inst $)$

The model in equation 1 can be specific in its explicit form showing the various parameters to be estimated 
empirically;

Eprd $_{t}=\beta_{0}+\beta_{1}$ clmc $_{t}+\beta_{2}$ gpci $_{t}+\beta_{3} p w l_{t}+\beta_{4}$ invt $_{t}+\beta_{5}$ estr $_{t}+\beta_{6}$ tech $_{t}+\beta_{7}$ inst $_{t}+\varepsilon_{t}$

where $\operatorname{Eprd}_{t}$ is energy production measured in kilowatt tons of oil equivalent, $c \operatorname{lm} c_{t}$ is carbon dioxide emissions in metric tons per capita, $g p c i_{t}$ is GDP per capita, $p w l s_{t}$ is the power production and distribution losses, $i n v t_{t}$ is investment is government funding, estr $r_{t}$ is a measure of the economic structure, $t e c h_{t}$ is the level of technology, inst $_{t}$ measures the strength of institutional quality and $\varepsilon_{t}$ captures the stochastic term.

Since energy production entails the process of generating, distribution and supply of energy to the end users, the inclusion of power losses, $p w l s_{t}$, is relevant in the model as share of power losses in total power produced linger around 40 percent to 45 percent in the period 1990-2010. The parameter $\beta_{3}$ of the variable is expected to be negative, as continuous power losses impede the amount of energy available for consumption. According to Oyedepo (2012), per capita energy consumption is a measure of the per capita income as well as a measure of the prosperity of a nation. It implies that demand for energy tends to rise with rapid population growth and increase in the standard of living of the society; this hereby necessitate the inclusion of GDP per capita in determining the level of energy production. Therefore, the parameter $\beta_{2}$ is expected to be positively related with energy production. In the same manner, energy has been adjudged a major driving force of SMEs and socioeconomic development of the emerging economies. Since energy also fuels productive activities like commerce, manufacturing and industry, the structure of an economy with respect to concentration of either manufactured or commodity export determines the extent of investment channel towards energy production and adapting of new energy sources; also weak institutions and regulatory quality has thwarted the minimal investment effort in the energy sector. It therefore implies that the parameters $\beta_{4}, \beta_{5}, \beta_{7}$ can either be positive or negative. If the parameters are negative, it implies an unproductive investment, economic concentration on primary export and weak institutions respectively. Finally, energy production has been impeded by frequent breakdown arising from the use outdated and heavily loaded equipments. Though, Nigeria is described primarily as an energy store house accommodating resources such as coal and lignite, natural gas, crude oil, solar, hydro, nuclear, woodfuel, geothermal, tide, and biogas. spite of the available vast resources, only three sources (crude oil, natural gas and hydro) are currently utilized in processed forms while two others (woodfuel, coal, solar etc) are used in their crude forms for heating, cooking and lighting (Ogundipe and Apata, 2013). There is need to develop appropriate technologies needed to diversify energy sources, adopt new available technologies to reduce wastages and save cost. From the foregoing, we expect the parameter $\beta_{6}$ to be positive.

\section{$5.1 \quad$ Technique of estimation}

In an attempt to investigate the effect of climate change on energy production in Nigeria, the study shall adopt the vector error correction procedure. Here, the co-integration analysis based on the Johansen and Juselius approach and Engle-Granger two step analyses was conducted to ascertain the long run equilibrium relationship in the model. Hence, we proceed to estimate the error correction mechanism in order to obtain the speed of error adjustment in long run convergence. Finally, we estimate the vector granger causality test in order to determine the directional of causal relationship among the variables specified in the model, especially between the regressor and regresands in the system.

\subsubsection{Unit Root Test}

Since most economic variables used for policy analysis and forecasting are characterized by persistence and possibly non-stationary behavior. It becomes pertinent to subject these series to pre-test for unit roots in order to determine the appropriate transformation that renders the data stationary (Gospodinov et al, 2013). In accessing the unit root properties, we assume a random walk model (RWM):

$Y_{t}=\rho Y_{t}+u_{t} \quad-1 \leq \rho \leq 1 \ldots \ldots \ldots \ldots \ldots \ldots \ldots$ (3)
Where $Y_{t}$ is a vector of the variables specified in the model, such that, $Y_{t}=\left\{\begin{array}{l}E p r d_{t} \\ \text { clmc }_{t} \\ g p c i_{t} \\ \text { pwls } \\ \text { invt }_{t} \\ \text { tech } \\ \text { inst }_{t}\end{array}\right\}$

In the equation 3, we simply regress $Y_{t}$ on its one-period lagged value $Y_{t-1}$ and find out if estimated $\rho$ is statistically equal to 1 ; if the latter condition is satisfied, then $Y_{t}$ is stationary. For ease of estimation of the equation above using OLS, it is hereby transformed as follows:

$$
\Delta Y_{t}=\delta Y_{t-1}+u_{t}
$$

Where $\delta=(\rho-1)$ and $\Delta$ represents the first difference operator. We proceed to estimate equation above and test the null hypothesis that $\delta=0$, and the alternative hypothesis that $\delta<0$. if $\delta=0$, then $\rho=1$; this implies the existence of a unit root and suggests that the series is non-stationary. Based on the model above, Dickey and 
Fuller (1979) provided an alternative decision making using critical values of tau statistics on the basis of Monte Carlo Simulations. The Dickey-Fuller test assumed that the error term $u_{t}$ was uncorrelated, but in situation where $u_{t}$ are correlated; an advanced unit root test was developed known as the augmented Dickey-fuller (ADF) test.The study adopted this new variant of unit root test in order to select appropriate lag length required to overcome the problem of serial correlation in the error term. The ADF test augments the equation above by including the lagged values of the dependent variable $\Delta Y_{t}$.

$\Delta Y_{t}=\beta_{1}+\beta_{2} t+\delta Y_{t-1}+\sum_{i=1}^{m} \alpha_{i} \Delta Y_{t-i}+\varepsilon_{t}$

Where $\Delta Y_{t-1}=\left(Y_{t-1}-Y_{t-2}\right), \varepsilon_{t}$ is a pure white noise error term. The number of lags to be included is determined empirically. Often times, researchers include the required number of lags necessary to ensure that the error term is serially uncorrelated and leading to an unbiased estimate for $\delta$ (the coefficient of lagged $Y_{t-1}$ ).

However, the Philip-perron test uses nonparametric statistical methods to take care of the serial correlation in the error terms without adding lagged difference terms. Both ADF and PP share similar asymptotic distribution.

\subsubsection{Johansen Co-integration test}

The Johansen methodology takes its root in the vector autoregressive (VAR) of order $p$ given by:

$Y_{t}=N+A_{1} Y_{t-1}+\ldots \ldots \ldots \ldots+A_{p} Y_{t-p}+\varepsilon_{t}$

Where $Y_{t}$ is an $n * 1$ vector of variables that are integrated of order one (denoted as $\mathrm{I}(1)$ ) and $\varepsilon_{t}$ is an $n * 1$ vector of innovations. The VAR specification can be represented as follow:

$\Delta Y_{t}=\mu+\pi_{y_{t-1}}+\sum_{i=1}^{p-1} \Gamma_{i} \Delta y_{t-1}+\varepsilon_{t}$

Where $\Pi=\sum_{i=1}^{p} A_{i}-\mathrm{I}$ and $\Gamma_{i}=-\sum_{j=i+1}^{p} A_{j}$

If the coefficient matrix $\Pi$ has reduced rank $r<n$, then there exist $n * r$ matrices $\alpha$ and $\beta$ each with rank $r$ such that $\Pi=\alpha \beta^{\prime}$ and $\beta^{\prime} Y_{t}$ is stationary.ris the number of co-integrating relationships, the elements of $\alpha$ are known as the adjustment parameters in the vector correction model and each column of $\beta$ is a co-integrating vector. The Johansen approach proposes two different likelihood ratio tests of the significance of these canonical correlations and thereby the reduced rank of $\Pi$ matrix. The trace test and maximum eigenvalue test statistics are shown below:

$J_{\text {trace }}=-T \sum_{i=r+1}^{n} \ln \left(1-\lambda_{i}\right)$

$J_{\max }=-T \ln \left(1-\lambda_{r+1}\right)$

Where $\mathrm{T}$ is the sample size and $\lambda_{i}$ is the $i$ : th largest canonical correlation. The trace test tests the null hypothesis of $r$ cointegrating vectors against the alternative hypothesis of $n$ cointegrating vectors while the maximum eigenvalue test tests the null hypothesis of $\mathrm{r}$ co-integrating vector against the alternative hypothesis of $r+1$ cointegrating vectors. The Johansen methodology as modified by Johansen and Juselius (1990) gives asymptotic critical values, the critical values as used by the maximum eigenvalue and trace test statistics are based on a pure unit root assumption. The test statistics will no longer be correct if variables in the system are near unit root processes (Hjalmarson and Osterholm, 2007). For the purpose of ensuring robustness, the engle-granger two-step procedure was adopted to corroborate the findings from the Johansen methodology.

\subsubsection{Error Correction Model}

The error correction model is a dynamic system with the characteristics that deviation of the current state from its long run relationship will be fed into the short run dynamics. The Error Correction Model (ECM) are category of multiple time series models that directly estimate the speed at which the dependent variable,Eprd ${ }_{t}$, returns to equilibrium after a change in the independent variables. The basic structure of the error correction model is demonstrated below:

$\Delta Y_{t}=\alpha+\beta \Delta X_{t-1}+\beta E C_{t-1}+\varepsilon_{t}$

Where $E C$ is the error correction component of the model and measures the speed at which prior deviations from equilibrium are corrected.

\subsubsection{Granger Causality test}

We employ the granger causality test for determining whether one time series is useful in forecasting another. A variable $x$ is said to granger cause another $\mathrm{y}$ if past values of $\mathrm{x}$ help predict the current level of $\mathrm{y}$ given all other appropriate information. Two variables may be contemporaneously correlated by chance but it is unlikely that the past values of $x$ will be useful in predicting $y$, given all the past values of $y$, unless $x$ does actually cause $y$ in a philosophical sense. Similarly, if $y$ in fact causes $x$, then given the past history of $y$ it is unlikely that information on $x$ will help predict $y$. Granger causality is not identical to causation in the classical philosophical sense, but it does demonstrate the likelihood of such causation or lack of such causation more forcefully than does simple contemporaneous correlation (Geweke, 1984). The model for granger causality test requires estimating the following:

$Y_{t}=\beta_{1,0}+\sum_{i=1}^{p} \beta_{1 i}, y_{t-1}+\sum_{j=1}^{p} \beta_{1, P+j} X_{t-j}+\varepsilon_{1 t}$ 
$X_{t}=\beta_{2,0}+\sum_{i=1}^{p} \beta_{2 i}, y_{t-1}+\sum_{j=1}^{p} \beta_{2, P+j} X_{t-j}+\varepsilon_{1 t}$

Where $p$ is the number of lags that adequately models the dynamic structure so that the coefficient of further lags of variables are not statistically significant and the $\varepsilon$ is the white noise. If the $p$ parameters $\beta_{1, P+j}$ are jointly significant then the null hypothesis that $X$ does not Granger cause $Y$ can be rejected. Similarly, if the $p$ parameter $\beta_{2, i}$ are jointly significant then the null hypothesis that $Y$ does not Granger cause $X$ can be rejected.

\section{$5.2 \quad$ Data sources and Measurement}

The study covers the period of 1970 to 2012 using annual time series data from theWorld Bank Development Indicators (WDI) of the World Bank, the World Governance Indicator (WGI)of the World Band, United Nations Conference on Trade and Development (UNCTAD) and data market of Iceland available at http://datamarket.com/.

Table 2: Data sources and measurements

\begin{tabular}{|c|c|c|c|}
\hline Variable & Symbol & Sources & measurement \\
\hline Energy production & Eprd & World Development Indicators (WDI) & Kilowatt tons of oil equivalent \\
\hline Climate change & Clmc & World Development Indicators (WDI) & $\mathrm{CO}_{2}$ emissions in Kilowatt tons \\
\hline GDP Per Capita & $G p c i$ & World Development Indicators (WDI) & Constant \$US \\
\hline Power losses & Pwls & World Development Indicators (WDI) & Units \\
\hline Economic structure & Estr & UNCTAD & $\begin{array}{l}\text { Share of primary export in } \\
\text { total merchandise export }\end{array}$ \\
\hline Technological level & Tech & Data market of Iceland & $\begin{array}{l}\text { Number of fixed and mobile } \\
\text { telephone line subscriber }\end{array}$ \\
\hline Institution quality & Tnst & World Governance Indicators & $\begin{array}{l}\text { Estimates of governance } \\
\text { effectiveness }\end{array}$ \\
\hline
\end{tabular}

\subsection{Discussion of Results}

This section presents the results obtained from the empirical investigation of the model specified earlier; we begin the section by examining cross correlation among our explanatory variables. The study adopted the pair wise correlation matrix and the variance inflation factor to test for the existence collinear relationship among the explanatory variable (see table $3 \& 4$ ). The results readily available indicate that multicollinearity does not exist in the model; hence the estimates from the model can be relied upon.

Table 3: Pairwise correlation matrix

\begin{tabular}{llllllll}
\hline variable & dlinvt & dlgpci & dlpwls & dlestr & dltech & dlclmc & dinst \\
\hline dlinvt & 1.0000 & & & & & & \\
dlgpci & 0.1165 & 1.0000 & & & & & \\
dlpwls & -0.1312 & 0.0944 & 1.0000 & & & & \\
dlestr & 0.0066 & 0.1685 & -0.0540 & 1.0000 & & & \\
dltech & -0.1981 & 0.0777 & -0.2333 & -0.1333 & 1.0000 & & \\
dlclmc & -0.3591 & -0.0114 & 0.1817 & 0.0313 & 0.1350 & 1.0000 & 0.0000 \\
dinst & 0.0847 & 0.1946 & 0.0915 & 0.0044 & 0.1486 & 0.0607 & \\
\hline
\end{tabular}

Source: Computed by authors using stata 10.0

As seen in table 3, correlation among the explanatory variable is seem to be weak with the maximum being around 19 per cent between institution quality and GDP per capita. A high or perfect collinear relationship among explanatory variables tends to be very problematic and violates the basic classical assumption of regression model. The variance inflation factor and tolerance factor, as contained in table 4, confirms the evidence of no perfect collinearity obtained using the pair wise correlation in table 3 .

Table 4: variance inflation factor

\begin{tabular}{|l|l|l|}
\hline Variable & Vif & $1 /$ vif \\
\hline dlinvt & 1.25 & 0.7996 \\
\hline dlgpci & 1.24 & 0.8068 \\
\hline dlpwls & 1.20 & 0.8348 \\
\hline dlestr & 1.19 & 0.8400 \\
\hline dltech & 1.12 & 0.8959 \\
\hline dlclmc & 1.09 & 0.9148 \\
\hline dinst & 1.08 & 0.9295 \\
\hline
\end{tabular}

Source: Computed by authors using stata 10.0

We start the empirical process by examining the time series properties of the variables used in the model by conducting a unit root test based on Augmented Dickey Fuller (ADF) and Philip Perron (PP) procedure. These procedures tests whether a time series variable is non-stationary using an autoregressive model. Both ADF and PP test tests the null hypothesis of the existence of unit root in the variables. 
Table 5: Stationary test

\begin{tabular}{|c|c|c|c|c|c|}
\hline \multicolumn{6}{|c|}{ UNIT ROOT TEST } \\
\hline \multirow[t]{2}{*}{ Variables } & & \multicolumn{2}{|c|}{ Level } & \multicolumn{2}{|c|}{ First Difference } \\
\hline & & $\mathrm{ADF}$ & $\mathrm{PP}$ & $\mathrm{ADF}$ & $\mathrm{PP}$ \\
\hline DLEPRD & & -0.2931 & -0.1380 & -6.5260 & -6.6265 \\
\hline DLINVT & & 1.8277 & -0.6035 & -7.8306 & -7.9160 \\
\hline DLGPCI & & 2.7735 & 6.8488 & -7.0016 & -4.4505 \\
\hline DLPWLS & & -2.1522 & -2.0099 & -9.2644 & -9.4996 \\
\hline DLTECH & & 3.0842 & 1.5172 & -13.1128 & -2.4549 \\
\hline DLESTR & & -4.1556 & -4.0509 & -7.5693 & -12.9083 \\
\hline DLCLMC & & -2.1518 & -2.0783 & -7.7262 & -7.9352 \\
\hline DINST & & -2.8668 & -2.8897 & -6.7628 & -6.8290 \\
\hline Critical & $1 \%$ & -3.6010 & -3.6010 & -3.6056 & -3.6056 \\
\hline Values & $5 \%$ & -2.9350 & -2.9350 & -2.9369 & -2.9369 \\
\hline & $10 \%$ & -2.6058 & -2.6058 & -2.6069 & -2.6069 \\
\hline
\end{tabular}

Note: $\quad$ ADF- Augmented Dickey Fuller test, using lag length of 1 and SIC maxlag of 9

PP- Phillip Perron test, bandmoth of 3 (newey-west automatic) using Bartlett kernel

$H_{0}$ :there is unit root and time series is non-stationary $K=0 \rightarrow(1-\Psi)=0$

$H_{1}$ :there is no unit root and time series is stationary $K<0 \rightarrow(1-\Psi)<0 \rightarrow \Psi<1$

As indicated in table 5 , all the variables were not stationary at level except the indicator of economic structure.

This implies the existence of unit root at I $(0)$ and we failed to reject the null hypothesis; this is not unexpected as most economic variables exhibit a very high persistence and non-stationary behavior. In order to obtain a stationary behavior, we subjected the series to differencing and obtain stationary for all the variables at first order of integration, i.e. I(1). Hence, we reject the null hypothesis and accept the alternative of pure unit root processes. This process of differencing our series to obtain stationary series becomes imperative in order to avoid spurious regression and biased estimates that could mislead policy analysis and forecasting.

Having obtained a stationary series, we hereby proceed to ascertain the long run stationary of our model using Johansen co-integrating rank test, and the engle-granger residual stationary test. These two tests confirm the existence of a unique co-integrating equation in the model. We are able to ascertain this by using the trace statistics and the residual stationary test as specified in the Johansen rank test and Engel-granger residual test respectively. As contained in table 6 , there exist the a unique co-integrating vector at 5 percent level of significant for the trace statistics while the maximum eigenvalue statistics could not produce a unique cointegrating vector. In accordance to the trace statistics, the engle-granger technique reveals the existence of long run equilibrium relationship; the relationship holds sway even with interacted variable.

Table 6: Co-integration test

Johansen and Juselius Maximum likelihood Co-integration Rank test

\begin{tabular}{llllll}
\hline Eigen value & Trace statistics & Max. statistics & $\begin{array}{l}\text { CV@ } 0 \% \\
\text { Trace }\end{array}$ & $\begin{array}{l}\text { CV @ 5\% } \\
\text { Max. }\end{array}$ & Hypothesized No. of CE(s) \\
0.864302 & 242.9249 & 77.89549 & 169.5991 & 53.18784 & None* \\
0.681501 & 165.0294 & 44.62133 & 134.6780 & 47.07897 & At most 1 \\
0.653618 & 120.4081 & 41.34830 & 103.8473 & 41.07897 & At most 2 \\
0.561257 & 79.05976 & 32.12935 & 76.97277 & 32.12985 & At most 3 \\
0.410223 & 46.92990 & 20.59239 & 54.07904 & 20.59239 & At most 4 \\
0.314611 & 26.33751 & 14.73296 & 35.19275 & 14.73296 & At most 5 \\
0.194798 & 11.60455 & 8.449799 & 20.26184 & 8.449799 & At most 6 \\
0.077706 & 3.154751 & 3.154751 & 9.164546 & 3.154751 & At most 7
\end{tabular}

Engle-Granger Co-integration Residual long-run test

$\begin{array}{lllllll}\text { Variable } & \text { coefficient } & \text { Std. error } & \text { t-statistics } & \text { CV @ 1\% } & \text { CV @ 5\% } & \text { Prob.* } \\ \text { ECM (-1) } & -0.9702 & 0.1586 & -6.1179 & -3.6056 & -2.9369 & 0.0000 \\ \text { C } & -0.0022 & 0.0104 & -0.2121 & & & 0.8332\end{array}$

Engle-Granger Co-integration Residual long-run test (with interacted variable)

\begin{tabular}{lllllll} 
Variable & coefficient & Std. error & t-statistics & CV @ 1\% & CV @ 5\% & Prob. $^{*}$ \\
ECM (-1) & -1.0032 & 0.1558 & -6.4391 & -3.6056 & -2.9369 & 0.0000 \\
C & -0.0030 & 0.0109 & -0.2799 & & & 0.8332 \\
\hline
\end{tabular}

Source: Computed by authors using eviews 7.0 
Table 7 reveals the result of the long run normalized coefficients; the result indicates the magnitude and pattern of long run equilibrium behavior of our model. Here, the table shows an evidence of a significant inelastic response of climate change on energy production, this implies that a change in climate brings about a less proportionate change in the level of energy produced. In the same manner, a positive relationship exists between climate change and energy production. The sign of the indicator of climate change failed to confirm to our a priori expectation, and this might not be unconnected to the recent heavy reliant on crude oil and natural gas (thermal) as the major source of energy in Nigeria, and since gas flaring still remain predominant in Nigeria; it therefore implies that the process of extracting and refining more oil also leads to greater emission. Also another strand of argument that could have generated the result obtain is centered on the fact that inadequate power supply has necessitated domestic and household reliant on power generating plants which has recently constituted a major source of urban pollution in Nigeria. As indicated in the result of table 7, the long-run elasticity of energy production growth with respect to climate change is 0.38 percent, indicating that for each observable change in climate, energy production growth rise by 0.38 percent. This result conforms to the findings of Nnaji, Chukwu and Moses (2013); and Omisakin (2009) as observed in studies conducted in Nigeria. Table 7: Normalized co-integration estimates

\begin{tabular}{lllllllll}
\hline \multicolumn{8}{c}{ Co-integrating coefficient normalized on Energy Production } \\
\hline DLEPRD & DLINVT & DLGPCI & DLPWLS & DLTECH & DLESTR & DLCLMC & DINST & C \\
1.000000 & 0.0391 & -0.3810 & 0.1222 & 0.0876 & -0.3828 & -0.3536 & -0.5105 & 0.0197 \\
& $(0.0176)$ & $(0.0536)$ & $(0.0211)$ & $(0.0245)$ & $(1.4088)$ & $(0.0485)$ & $(0.0965)$ & $(0.0107)$ \\
Prob. $*$ & 2.22 & -7.11 & 5.80 & 3.58 & -0.27 & -7.29 & -5.29 & 1.84 \\
\hline
\end{tabular}

Source: Computed by authors using eviews 7.0

Note: Since the Johansen co-integation test assumes all variables as endogenous, we alternate the signs of the magnitudes.

In order to control for the role of institutions, we attempted an interaction of the indicator of climate change with institutions (governance effectiveness) to generate a new variable. This new variable is stated as (clmc_inst) in table 8 . The interacted variable share similar features with the actual climate change indicator; it impacted a significant inelastic variation on energy production, though it impacted a lesser proportionate change on energy production than actual climate change. It hereby implies that strengthening of institutional quality can mitigate the impact of climate change on energy production. Also from table 8 , it is obvious that investment, though statistically significant, it varies negatively with energy production. This could be deduced from the insufficient funding, gross mismanagement and diversion of funds that marred the sector hitherto. Likewise, power losses and technological level exerted a significant negative impact on energy production. This results from the fact that as population grows and societal welfare improves, there is need for more energy consumption; and generation and distributional losses lessen the level of energy available for use. Government effectiveness as a measure of institutions exerts a positive significant impact on energy production, it is worthy of note that the long run elasticity of energy production growth with respect to institutions is the highest in the model amounting to 0.5 percent. This indicates that for any change in institutions quality, energy production growth rise by 0.5 percent. This confirms the strand of theory that adjudged strong institutions as pertinent to extractive developing economies. Finally, the structure of the economy does not seem to influence energy production significantly.

Table 8: Normalized co-integration estimates (with interacted variable)

Co-integrating coefficient normalized on Energy Production (with interacted variable)

\begin{tabular}{llllllll}
\hline DLEPRD & DLINVT & DLGPCI & DLPWLS & DLTECH & DLESTR & CLMC_INST & C \\
1.000000 & 0.195992 & -0.8309 & 0.1398 & 0.1348 & -3.8670 & -2.1078 & 0.0799 \\
& $(0.0318)$ & $(0.0941)$ & $(0.0371)$ & $(0.0441)$ & $(2.4157)$ & $(0.6414)$ & $(0.0192)$ \\
Prob.* & 6.16 & -8.83 & 3.77 & 3.06 & -1.60 & -3.29 & 4.17 \\
\hline
\end{tabular}

Source: Computed by authors using eviews 7.0

Note: Since the Johansen co-integration test assumes all variables as endogenous, we alternate the signs of the magnitudes.

We estimate the equilibrium vector error correction in attempts to adjust the disequilibrium in the co-integrating relationship. This is based on the logic that a longrun relationship exists and that there are disturbances in the short-run which needs adjustment back to long run equilibrium (Alege and Ogundipe, 2013). 
Table 9: Equilibrium Vector Error Correction

\begin{tabular}{lllllllll}
\hline \multicolumn{1}{c}{ Vector Error Correction Model for Energy Production } \\
\hline Variable & D(DLEPRD) & D(DLINVT) & D(DLGPCI) & D(DLPWLS) & D(DLTECH) & D(DLESTR) & D(DCLMC) & D(DINST) \\
ECT_1 & -0.4081 & -2.7378 & 0.3829 & -2.0762 & -0.6875 & 0.07607 & 0.8886 & 0.4744 \\
& $(0.2153)$ & $(1.3664)$ & $(1.4792)$ & $(1.4792)$ & $(0.3213)$ & $(0.0169)$ & $(0.5213)$ & $(0.2625)$ \\
& {$[-1.896]$} & {$[-2.0037]$} & {$[-1.4036]$} & {$[-1.4036]$} & {$[-2.1400]$} & {$[4.4838]$} & {$[1.7047]$} & {$[1.8069]$} \\
\hline
\end{tabular}

Source: Computed by authors using eviews 7.0

The coefficient of the $\operatorname{ECM}(-1)$ as seen in table 9 conforms with the theoretical stand, as it is correctly signed (negative), statistically significant and its absolute magnitude being between 1 and 0 . It shows that the model has a self-adjusting mechanism for correcting short-run dynamics in the series to their long run path. With the $\operatorname{ECM}(-1)$ satisfying the rule of thumb, we can conclude that there exist a long run converging relationship between energy production and its determinants. The ECM $(-1)$ reveals that about 40.8 percent of short run disturbances are adjusted back to equilibrium path in the long run. The speed of error correction tends to be moderate; the statistical significance at about 10 percent significance level and magnitude of 40.8 percent indicates that that a deviation in energy production from equilibrium is corrected by 40.8 percent in the successive period.

Table 10: Equilibrium Error Correction (interacted variable)

\begin{tabular}{llllllll}
\hline \multicolumn{7}{c}{ Vector Error Correction Model for Energy Production } \\
\hline Variable & D(DLEPRD) & D(DLINVT) & D(DLGPCI) & D(DLPWLS) & D(DLTECH) & D(DLESTR) & D(CLMC_INST) \\
ECT_1 & -0.2870 & -2.5704 & 0.7512 & -1.3967 & -0.4063 & 0.04617 & 0.0387 \\
& $(0.1460)$ & $(0.9307)$ & $(0.2805)$ & $(1.0044)$ & $(0.2226)$ & $(0.0123)$ & $(0.0450)$ \\
& {$[-1.9658]$} & {$[-2.7620]$} & {$[2.6782]$} & {$[-1.3905]$} & {$[-1.8253]$} & {$[3.7640]$} & {$[0.8629]$}
\end{tabular}

Source: Computed by authors using eviews 7.0

Also, in the model with the interacted variable, $\operatorname{ECM}(-1)$ conforms to the rule of thumb. In this case, speed of error correction seems to be sluggish as about 29 percent of disturbances encountered in the short run are adjusted back to the long run equilibrium path indicating that the error in the model exhibited some form of long memory and weak reversion.

The results in table 11 present the granger causality test for energy production and its determinants. The Wald exogeneity test was adopted to test the null hypothesis of no causality and the probability value gives the decision rule concerning the direction of causality.

Table 11: Wald Exogeneity Causality test

\begin{tabular}{|l|l|l|l|l|}
\hline Null hypothesis & Chi2 & Prob.* & Decision & Causality \\
\hline dlinvt does not Granger Cause dleprd & 1.3171 & 0.2511 & Accept & None \\
dleprd does not Granger Cause dlinvt & 0.1381 & 0.7102 & Accept & \\
\hline dlgpci does not Granger Cause dleprd & 1.0212 & 0.3122 & Accept & None \\
dleprd does not Granger Cause dlgpci & 2.1082 & 0.1465 & Accept & \\
\hline dlpwls does not Granger Cause dleprd & 0.0297 & 0.8631 & Accept & Unidirectional \\
dleprd does not Granger Cause dlpwls & 3.6927 & 0.0547 & Reject & \\
\hline dltech does not Granger Cause dleprd & 8.1176 & 0.0044 & Reject & Unidirectional \\
dleprd does not Granger Cause dltech & 0.3806 & 0.5373 & Accept & \\
\hline dlestr does not Granger Cause dleprd & 4.4172 & 0.0356 & Reject & Unidirectional \\
dleprd does not Granger Cause dlestr & 0.0483 & 0.8260 & Accept & \\
\hline dlcmlc does not Granger Cause dleprd & 0.0398 & 0.8418 & Accept & None \\
dleprd does not Granger Cause dlcmlc & 0.0003 & 0.9869 & Accept & \\
\hline
\end{tabular}

Source: Computed by authors using eviews 7.0

Table 11 indicates a unidirectional causal relationship running from energy production to power losses without feedback indicating that changes in energy production affects power losses. This implies that as the economy adapts new energy sources and replaces obsolete power generation and distribution equipments, the level of energy losses tends to be mitigated. Likewise, there is an evidence of unidirectional causality running from technological level to energy production; this implies that change in the level of technology affects energy production. It is therefore imperative for government to investment in relevant technologies to ensure full utilization of all forms of energy sources and training of personnel in order to confront technical problems and adequate maintenance of power stations which in the words of Oyedepo (2012) is the reason why most of the existing electricity plants in Nigeria are underutilized or not functioning at all. Interesting evidence from our result is the absence of a causal relationship between climate change and energy production. This will not be 
unconnected with the reality that the effect of climate change is predominate on hydro energy sources but a larger proportion of energy source in Nigeria comes from oil and natural gas (thermal).

In order to ensure the reliability of our result estimates, we conducted a number of result robustness checks. This helps to ascertain that policy implications arising from our study is not misleading and forecasting can be absolutely relied on.

Table 12: Robustness Checks

VEC Residual heteroskedasticity tests (Joint variable test)

\begin{tabular}{lll}
\hline Chi-sq & Df & Prob.* \\
455.7163 & 448 & 0.3903
\end{tabular}

VEC Residual Normality test: Skewness

Chi-sq Prob.*

$-8.8023 \quad 0.2672$

VEC Residual Normality test: Kurtosis

Chi-sq

4.2213

Prob.*

VEC Residual Normality test: Jarque-Bera

$\begin{array}{ll}\text { Chi-sq } & \text { Prob.* } \\ 13.0236 & 0.5247\end{array}$

Source: Computed by authors using eviews 7.0

The study conducted the vector residual heteroskedasticity test; here we test the null hypothesis for the presence of heteroskedasticity. The insignificance of the probability value as shown in table 12 suggests the rejection of the null hypothesis and concludes the presence of homoskedaticity. Likewise, we collaborated this, by plotting the residual graph and could not observe any known pattern for the residuals. In the same manner, the Skewness, Kurtosis and Jerque-Bera statistics were used to test the normality of the series used in the regression analysis and interestingly the study failed to accept the null hypothesis of no normality.

Table 13: LM Serial Correlation test

\begin{tabular}{lll}
\hline Lags & LM statistics & Prob.* \\
\hline 1 & 41.8456 & 0.7538 \\
2 & 60.1924 & 0.1312 \\
3 & 40.2835 & 0.8080 \\
4 & 62.7673 & 0.0894 \\
5 & 49.2237 & 0.4642 \\
6 & 61.9111 & 0.1019 \\
7 & 34.2281 & 0.9457 \\
8 & 64.1691 & 0.0717 \\
9 & 51.3125 & 0.3832 \\
10 & 69.6457 & 0.0278 \\
\hline Source
\end{tabular}

Source: compiled by authors using eviews 7.0

Also, our study employed a sensitivity check to ensure the successive values of our error terms are not serially correlated at the level of lag(s) chosen in the regression procedure. The existence of serial correlation violates a major classical assumption of regression model and could produce unreliable and biased estimates. The study failed to reject the null hypothesis of no serial correlation at second lag, our model is hereby void of serial correlation and the estimates obtained is useful for policy inferences and forecasting.

\subsection{Recommendations and Conclusions}

This study investigated the impact of climate change on the energy sector with specific focus on energy supply. It examines how the incidence of climate change being widely experienced in most parts of the country, affects the supply of energy and invariably access to adequate energy. A number of studies and reports have indicated that in the face of the threat presented by changing climate, the supply of energy will be adversely affected. Applying contemporary econometric methods, the study found a positive relationship between climate change and energy supply. Though this might be against the a priori expectation that as climate change intensifies, energy production should fall.

However, the positive relationship between climate change and energy supply could be due to the nature of the energy industry in Nigeria (an oil-producing economy) with crude oil and natural gas reserves of 36.2 billion barrels and 166 trillion standard cubic feet (SCF). This enormous reserve has accentuated the reliance on oil and natural gas sources which is less susceptible to climate change. Also, evidence from causality test shows absence of causal relationship between climate change and energy production. This further affirms the result from the long run estimates, portraying the reality in Nigeria. Since climate change is adjudged to have significant impact 
on hydropower and the share of hydro source of energy has consistently dwindle in Nigeria being 15 percent of energy generated in 2011 while natural gas sources amount to 64 percent in the same year.

Our findings have strategic policy implications especially in regards to the Kyoto protocol commitment. In the light of these results, the policy makers and economic drivers in Nigeria needs to trend with caution on the level of productive activities and economic gains to sacrifice in order to ensure adherence to the Kyoto protocol.

Also, the interaction of climate change and institution quality denoted by variable name (clmc_inst) reveals a positive relationship between the interacted variable clmc_inst and elprd (energy production), even though energy production is less responsive to the interacted variable $(\mathrm{clmc}$ _inst). A strand of argument that could be valid is the fact that inadequate power supply has led household and businesses to alternative power sources which has contributed significantly to household and industrial pollution. As shown by the weaker influence of clmc_inst on elprd, it implies that strengthening of institutions is imperative to mitigate the impact influence of climate change.Also, there is need to ensure appropriate channeling of investment and enhance adoption of relevant technologies to diversify energy sources and develop more clean energy. There is need to intensify efforts at enhancing technological development in the energy sector so as to enhance energy supply as the lack of technological innovation has often be noted as one of the major challenge of the growth of the industry.

In light of the results obtained from this study, it is recommended that in intensifying the efforts at tackling climate change and reforming the energy sector for maximum productivity; adaptation efforts by government must be geared towards technological innovation in the industry with consented measures at ensuring adequate energy mix particularly from renewable sources. This is very important as the achievement of low-carbon economy hinges on the nature of energy mix to bring about sustainable development. All these must be within the framework of a strengthened institutional structure that will enhance their adequate implementation.

\section{REFERENCES}

Adenikinju, A. (2008). Efficiency of the Energy Sector and its Impact on the Competitiveness of the Nigerian Economy. International Association of Energy Economics. Fourth Quarter 2008.

Akinbami, J.F.K, (2009). Climate Change and Energy: Issues, Prospects and Challenges for Sustainable Development in Nigeria. Being a paper presented at "Capacity Building Workshop for House of Representatives' Committee on Climate Change and the Media" Kaduna.

Alege, P. O and Ogundipe, A. A (2013). Environmental Quality and Economic Growth in Nigeria: A Fractional Co-integration Analysis. International Journal of Development and Sustainability. Vol. 2, No. 2.

Ayodele, A. S, (2001). Improving and Sustaining Power (Electricity) Supply for Socio-economic Development in Nigeria.Retrieved December 20th, 2013 from www.cenbank.org/out/annual/ACZRU/2001.

Beecher, J. A, and Kalmbach, J. A, (2012). Climate Change and Energy.US National Climate Assessment Midwest Technical Input Report.

Building Nigeria's Response to Climate Change (BNRCC) Report (2011). National Adaptation Strategy and Plan of Action on Climate Change for Nigeria.Prepared for the Federal Ministry of Environment Special Climate Change Unit.

Chalvatzis, K. J. and Hooper, E. (2009). Energy Security versus Climate Change: Theoretical Framework Development and Experience in Selected EU Electricity Markets. Renewable and Sustainable Energy Reviews 13, 2703-2709.

Dickey, D. A and Fuller, W. A (1979). Distribution of the Estimators for Autoregressive Time Series with a Unit Root. Journal of the American Statistical Association, Vol 74, issue 366, 427-431.

Ebinger, J. and Vergara, W. (2011). Climate Impacts on Energy Systems: Key Issues for Energy Sector Adaptation. A World Bank Study and Energy Sector Management Assistance Programme.

Enete, C. I, and Alabi, M. O, (2011). Potential Impacts of Global Climate Change on Power and Energy Generation.Journal of Knowledge Management, Economics and Information Technology.Issue 6.

Enete, C. I, Officha, M. C, Ezezue, A. M. and Agbonome, P. C. (2012). Adapting Nigeria Cities to Climate Change Using Design Options: A Review. British Journal of Applied Science and Technology, 2(4), 367-378.

Geweke, J. (1984). Inference and causality in economic time series models. Handbook of Econometrics, in: Z. Griliches\& M. D. Intriligator (ed.), Handbook of Econometrics, edition 1, volume 2, chapter 19, pages 1101-1144 Elsevier.

Gospodinov, N., A. Herrera, and E. Pesavento (2013). Unit Roots, Co-integration and Pre-Testing in VAR Models, forthcoming: Advances in Econometrics.

Greenleaf, J, Harmsen, R, Angelini, T, Green, D, Williams, A, Rix, O, Lefevre, N, and Blyth, W. (2009). Analysis of Impacts of Climate Change Policies on Energy Security. Being final report of Ecofys, ERAS and RedPoint Energy by order of: European Commission DG Environment.

Gujba, H, Mulugetta, Y. and Azapagic, A. (2010). Environmental and Economic Appraisal of Power Generation Capacity Expansion Plan in Nigeria. Energy Policy 38, 5636-5652. 
Hjalmarson, E and Osterholm, P (2007). Testing for Co-integration using the Johansen Methodology when Variables are Near-Integrated. International Monetary Fund (IMF) Working Paper 07/141.

Ifeanyi-Obi, C. C, Etuk, U. R, and Jike-Wai, O. (2012). Climate Change, Effects and Adaptation Strategies: Implication for Agricultural Extension System in Nigeria. Greener Journal of Agricultural Sciences, vol. 2 (2), pp.53-60.

Iwayemi, A. (2008). Investment in Electricity Generation and Transmission in Nigeria: Issues and Options. Being a paper presented in the first quarter of 2008 in a summit organized by the International Association for Energy Economics, Ibadan, Nigeria.

Maddison, D. and Rehdanz, K. (2008). Carbon Emissions and Economic Growth: Homogenous Causality in Heterogeneous Panels. FNU Working Paper 163.

Matsuo Yuji, Suzuki Kengo, Nagatomi Yu, Suehiro Shigeru and Komiyama (2012). Estimating Global CO2 Emission Constraints and Energy Supply/Demand Structure in 2050 with MARKAL Model.IEEJ.Assessed 16/01/2014 at 1:45pm.

Millner, A. and Dietz, S. (2011). Adaptation to Climate Change and Economic Growth in Developing Countries. Center for Climate Change Economics and Policy Working Paper No, 69.

Nnaji, C. E., Chukwu, J. O, and Moses, N. (2013). Electricity Supply, Fossil Fuel Consumption, CO2 Emissions and Economic Growth: Implications and Policy Options for Sustainable Development in Nigeria. International Journal of Energy Economics and Policy. Vol. 3, No. 3, pp. 262-271.

Ogundipe, A. A and Apata, A .(2013). Electricity Consumption and Economic Growth in Nigeria. Journal of Business Management and Applied Economics.

Omisakin, O.A. (2009). Energy Consumption, Carbon Emissions and Economic Growth in Nigeria: A Bound Testing (ARDL) Co-integration Approach. Being Conference paper presented at the $2^{\text {nd }}$ Annual International Conference of Nigerian Association for Energy Economics, April 23-24, 2009, Abuja, Nigeria.

Onyeji, I. (2010). On the Determinants of Energy Poverty in Sub-Saharan Africa. AIAE Research Paper 5.African Institute for Applied Economics, Enugu.ISSN 079-4187.

Oricha, J. Y, and Olarinoye, G. A. (2012). Analysis of Interrelated Factors affecting Efficiency and Stability of Power Supply in Nigeria.International Journal of Energy Engineering, 2(1)1-8.

Osueke, C. O, and Ezeh, C. T. (2011). Assessment of Nigeria Power Sub-sector and Electricity Generation Projections.International Journal of Scientific and Engineering Research. Vol. 2, issue 11.

Oyedepo, S.A. (2012). On Energy for Sustainable Development in Nigeria.Renewable and Sustainable Energy Reviews 16, pp 2583-2598.

Sagar, A. D, Olivier, H. H, and Chikkatur, A. P. (2006). Climate Change, Energy and Developing Countries. Vermont Journal of Environmental Law, Spring Symposium Book.

Sathaye, J. O, Lucon, A, Rahman, J, Christensen, F, et al (2011). Renewable Energy in the Context of Sustainable Development.In IPCC Special Report on Renewable Energy Sources and Climate Change Mitigation. (O. Edenhofer, R. Pichs-Madruga et al, eds), Cambridge University Press, Cambridge, UK and New York.

Schaeffer, R, et al .(2011). Energy Sector Vulnerability to Climate Change: A Review. Energy 38.

Ubi, P. S, Effiom L, Okon, E, and Oduneka, A. E. (2012). An Econometric Analysis of the Determinants of Electricity Supply in Nigeria. International Journal of Business Administration.Vol. 3, No.4.

Ubi, P. S. and Effiom, L. (2013). The Dynamic Analysis of Electricity Supply and Economic Development: Lessons from Nigeria. Journal of Sustainable Society, vol. 2, no 1.1-11.

U.S Department of Energy (2013). US Energy Sector Vulnerabilities to Climate Change and Extreme Weather.DOE/PI-003.

Uzoma, C. C., Nnaji, C. E. and Nnaji, M. (2012). The Role of Energy Mix in Sustainable Development of Nigeria. Continental Journal of Social Sciences 5 (1): 21-29.

Wilbanks, T, et al (2012). Climate Change and Energy Supply and Use. Being a Technical Report to the US Department of Energy in Support of the National Climate Assessment.

World Energy Council (2007). Energy and Climate Change. London, United Kingdom. 